\title{
DATA HEAVEN
}

Moorea is one of the most studied ecosystems in the world. Myriad data collected over four decades will be used to build a digital replica of the island that includes its varied geography, its climate and all of its plant and animal life.
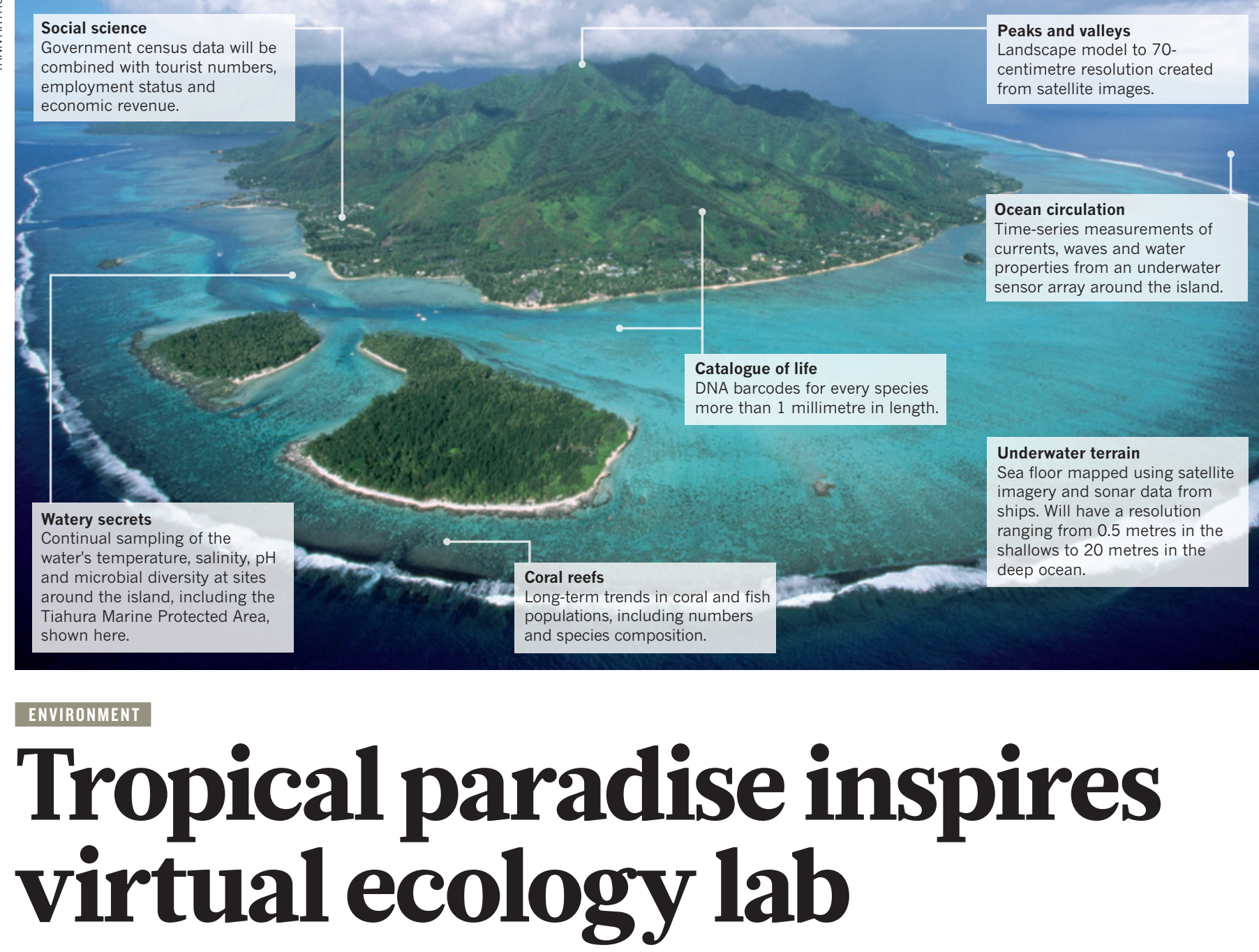

Digital version of Moorea will provide a way to experiment with an entire ecosystem.

\section{BY DANIEL CRESSEY}

A paradise on Earth could soon become the first ecosystem in the world to be replicated in digital form in painstaking detail, from the genes of its plants and animals to the geography of its landscape.

An international team is preparing to create a digital avatar of the Pacific island of Moorea, which lies off the coast of Tahiti and is part of French Polynesia. Moorea is already one of the most studied islands in the world; the team plans to turn those data into a virtual lab that would allow scientists to test and generate hypotheses about the impact of human activities.

Ecologists have used models for years to tease out the relationships between different facets of nature, such as temperature and population or predators and prey. But much of that modelling is relevant only to specific species or research questions, and some scientists want a holistic view. As human activity and natural variations combine to alter the environment, researchers need to know how mitigating steps - such as setting up protected areas, or attempts to curb fossil-fuel use - might affect an entire ecosystem.

"We know the world's changing. Yet the decisions we're making, we're making them in the dark," says Neil Davies, one of the people behind the Moorea IDEA (Island Digital Ecosystem Avatars) project and director of Gump Station, the University of California, Berkeley's marine-science base on the island. "We're not going to have precise predictions ever, but we need to have a way of modelling different scenarios." For example, if a hotel is built at a certain location, how does that change the ecosystem? If a species disappears from a river, what happens downstream?
Moorea is an ideal place to start, says Davies, because the island is about 16 kilometres across and has just 17,000 people living on it, making it easier to model than larger ecosystems and those that are more connected to the rest of the world. In addition, French researchers have been there since the 1970s, and Gump Station has been operating since the 1980s. Both efforts have collected myriad data on the island's waters, with decades-long studies of coral and fish numbers (see 'Data heaven').

These traditional surveys of marine life are now being linked up with the Moorea Biocode Project, which aims to characterize every species larger than a millimetre in length on the island and allocate them a 'DNA barcode' snippets of DNA that can be used as a unique identifier. Species can thus be identified quickly and easily even when they are in places or states that would otherwise be difficult 
to recognize, such as in the contents of another organism's stomach, or in seed or larval form.

The avatar would combine insights gleaned from the Biocode project - such as which species are present at certain ocean spots, or which species are eaten by another - with data on weather, ocean currents and society such as population density and real-estate prices. It would provide a threedimensional visualization of the island and its surrounding waters that might look something like those on Google Earth, but would enable researchers to zoom into a location, access data and run simulations.

"The first stage will be a framework to integrate the data we have. To collate them, combine them, and to make the data accessible to scientists," says project member Matthias Troyer, a computer scientist at the Swiss Federal Institute of Technology in Zurich. "Then, based on that, one can start on modelling."

\section{EXPANDING PROJECT}

The IDEA project was born in 2013, the brainchild of Davies, Troyer and three other marine scientists: Dawn Field at the University of Oxford, UK; Sally Holbrook at the University of California, Santa Barbara; and Serge Planes from the French research base on Moorea. The consortium now has more than 80 participants.

At meetings late last year, the IDEA team discussed how to combine existing data with those coming from the latest technologies. Some of the framework for the avatar is already under construction, and Davies says that the team is seeking funding of around US\$5 million over three years to pursue a pilot project.

The project is "really novel in the modelling community”, says Mike Harfoot, an ecosystem modeller at the United Nations Environment Programme's World Conservation Moni-

toring Centre in Cambridge, UK, because it will integrate societal data with physical and
"It's impressive the amount of data going into it." nents. And, he adds, the computational power required to take a holistic approach to modelling ecosystems has only recently become available.

"It's impressive the amount of data that's going in it," says Rick Stafford, a computational ecologist at Bournemouth University, UK. Getting the different data sets to talk to each other will be a challenge, but the time is ripe for such an ambitious undertaking, says Davies. And it if works on Moorea, the approach could be rolled out to other parts of the world. Although ambitious, says Davies, "it's not a pipe dream".

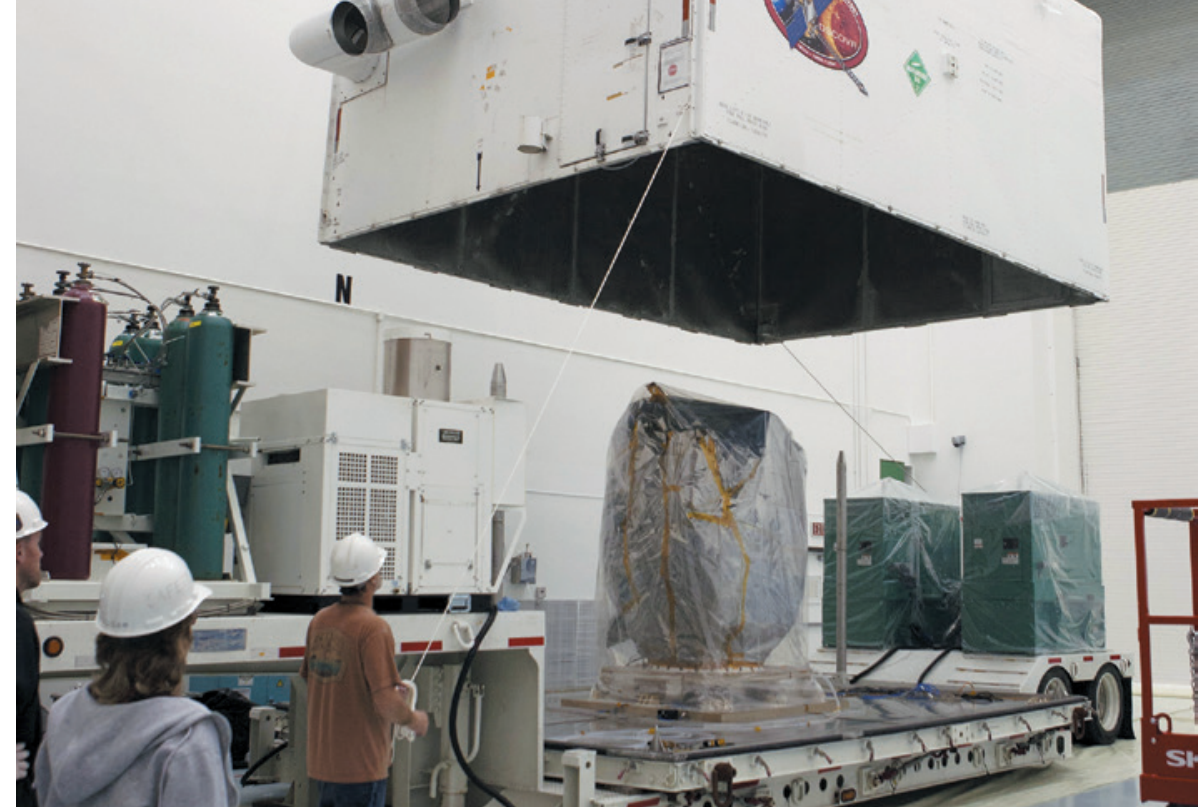

The DSCOVR craft is removed from a container in Cape Canaveral, Florida.

\section{SPACE}

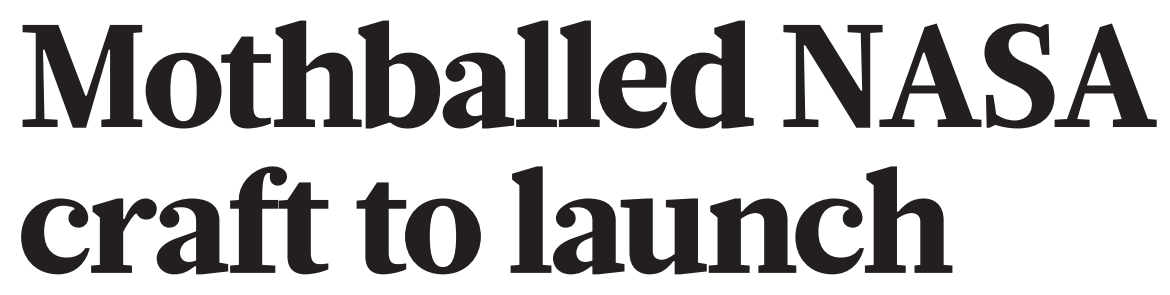

Proposed by former US vice-president Al Gore in 1998 to
image Earth, DSCOVR probe will monitor space weather.

\section{BY MARK ZASTROW}

A fter nearly 14 years in limbo, an Earthmonitoring spacecraft built by NASA is finally set to fly.

The Deep Space Climate Observatory (DSCOVR), scheduled to launch as soon as 29 January, will constantly observe Earth's sunlit side from a distance of 1.5 million kilometres. It will track daily weather patterns and seasonal vegetation changes, monitor atmospheric pollution and make the most precise measurements yet of how much energy Earth throws out into space - crucial data for the improvement of global climate models.

DSCOVR's resurrection is thanks to renewed interest in what was originally its secondary mission: monitoring space weather. From a point between the Sun and Earth at which the bodies' gravitational pulls cancel out, the probe will be able to detect approaching solar storms - bursts of charged particles and powerful radiation that pose a threat to astronauts, orbiting satellites and power grids on the ground. Such storms are of interest to the US Air Force, which is funding the satellite's launch, and the National Oceanic and Atmospheric Administration (NOAA), which will operate it.

DSCOVR was the brainchild of former US vice-president Al Gore. He imagined a probe that would beam down a live image of Earth's illuminated side that could be available online.
Just as the famous 'blue marble' image of Earth taken by the Apollo 17 crew had inspired people, Gore said in 1998 that DSCOVR would "awaken a new generation to the environment and educate millions of children around the globe".

To Gore's critics in Congress - particularly Republicans sceptical of his environmental advocacy - those were fighting words. The mission was nothing more than "a multimillion-dollar screen saver", said representative Dave Weldon (Republican, Florida). It acquired the unflattering nickname 'GoreSat'.

"The worst thing that can happen to science is to get mixed up in politics," says Francisco Valero, a retired climate scientist who was at the Scripps Institution of Oceanography in La Jolla, California, and led the satellite's original Earthscience team. "That is what happened to us."

Although Gore intended the project to be mostly educational, NASA formulated a complementary science mission by soliciting proposals from the community. Valero's winning pitch was a probe to measure how much radiation Earth reflects back into space, a crucial variable for untangling the web of processes that influence the planet's climate. Clouds, for example, are a perennial conundrum for climate models because they both reflect incoming sunlight and trap outgoing heat. Valero proposed two instruments: a camera called EPIC to image clouds and other climate-influencing factors such as pollution, volcanic ash and seasonal 